\title{
REFUGIADOS URBANOS: POLIITICA, POLÍCIA E RESISTÊNCIA NAS FRONTEIRAS DA CIDADE
}

\section{Urban refugees: politics, policing and resistance at cities' borders}

\author{
André Zuzarte* \\ Carolina Moulin**
}

\begin{abstract}
Resumo. Mais da metade dos refugiados no mundo encontra-se nas cidades. Como os debates críticos sobre a questão urbana dialogam com as temáticas recorrentes do campo de estudos sobre refúgio? Esse artigo busca promover um movimento preliminar de mapeamento de duas leituras prevalentes da questão dos refugiados urbanos, notadamente atreladas aos temas de proteção e às práticas de fronteirização e de resistência. De um lado, discute-se a cidade e o refúgio como experiências fortemente controladas e disciplinadas por aparatos institucionais, entendidas assim como dinâmicas de 'policiamento'. De outro, lê-se o urbano e a experiência do refúgio como espaços de transformação e de afirmação subjetiva da liberdade, delimitadas por processos de politização. A partir de exemplos, o artigo denota as possibilidades abertas pela inserção do urbano como dimensão central da condição refugiada contemporânea.
\end{abstract}

Palavras-chave: refugiados urbanos; política; resistência; cidade.

\begin{abstract}
More than half of the world's refugees now live in cities. How do critical urban studies dialogue with current debates in refugee studies? This paper advances a preliminary mapping of two recurring readings of the question of urban refugees, notably related to themes of protection, bordering practices and strategies of resistance. On one hand, we discuss the city and asylum as experiences controlled and disciplined by institutional apparatuses and framed as policing dynamics. On the other, we highlight narratives of the junction of the urban and of refugee populations as spaces of transformation and experiences of subjective affirmation of freedom, framed as practices of politicization. Based on examples, the paper explores the possibilities opened up by the insertion of the urban as a central dimension of the refugee condition today.
\end{abstract}

Keywords: urban refugees; politics; resistance; city.

Doutorando do Programa de Pós-Graduação em Relações Internacionais da PUC-Rio. Rio de Janeiro, RJ, Brasil.

Professora e Coordenadora do Programa de Pós-Graduação em Relações Internacionais, Instituto de Relações Internacionais, PUC-Rio. Rio de Janeiro, RJ, Brasil. 
A emergência da questão urbana para o tema do refúgio e da proteção às populações refugiadas ganhou proeminência significativa somente nas duas últimas décadas. Tradicionalmente pensados sob a lógica do 'campo' e da assistência humanitária em áreas rurais e sob ótica temporária (Ferris, 2011), refugiados urbanos foram vistos historicamente como exceção, a despeito do forte processo de urbanização experimentado globalmente desde a década de 1950. De fato, o Alto Comissariado das Nações Unidas para Refugiados (ACNUR), organismo internacional responsável pela promoção e proteção dos direitos das populações refugiadas, somente reconheceu a prioridade do tema dos refugiados urbanos em 2009, quando da reformulação de sua política para proteção e soluções para refugiados urbanos (ACNUR, 2009).

Estima-se que hoje, mais da metade das pessoas refugiadas no mundo vive em contextos urbanos - seja nas próprias cidades ou em suas cercanias ${ }^{1}$. Essa dinâmica apresenta enormes dificuldades para a assistência e acolhida. A dispersão territorial, a invisibilidade social, a heterogeneidade das dinâmicas sociais, espaciais e econômicas do urbano contemporâneo, acopladas à própria difusão, e por vezes sobreposição, das estruturas de governança e autoridade tornam a cidade um lócus particularmente desafiador aos atores que trabalham junto à população refugiada ${ }^{2}$. Mas cidades também mobilizam aberturas e potencialidades ao permitir (re)conexões sócio-espaciais, particularmente, a possibilidade de maior interação com a sociedade de acolhida e melhores oportunidades de inserção econômica e laboral, mesmo que em contextos de crescente precariedade. Acessos a serviços básicos e, inclusive, à própria estrutura burocrática do processo de solicitação de refúgio e de documentação são facilitados em contextos urbanos. No caso brasileiro, há relatos de refugiados em áreas rurais que acabaram migrando para cidades de grande e médio porte por incapacidade econômica e material de acesso ao sistema de elegibilidade (Facundo, 2017). Por vezes, cidades se tornam refúgios inescapáveis.

Esse contexto de emergência da questão dos refugiados urbanos e de sua saliência para o contexto brasileiro, haja vista que a grande maioria dos solicitantes de refúgio e refugiados estão concentrados nas áreas urbanas (ACNUR, 2017), convida a uma reflexão sobre como pensar o urbano sob

1 De acordo com o ACNUR, 58\% da população total de refugiados no mundo vive atualmente em áreas urbanas. Para saber mais: ACNUR, 2018.

2 Os campos, em geral, garantem maior capacidade de administração sobre a população refugiada ao confiná-la em um mesmo espaço e submetê-la a um rígido controle, restringindo parcialmente ou integralmente sua liberdade de movimento. As cidades, em contrapartida, são espaços mais dinâmicos, onde não é possível exercer um controle tão rígido sobre essa população. Em sua política de 2009, o ACNUR reafirma as facilidades que os campos oferecem em comparação ao meio urbano ao sublinhar que "nos campos de refugiados, o ACNUR e seus parceiros têm acesso mais fácil às pessoas assistidas, concentradas em espaços que, em alguns aspectos, são destinados a facilitar o fornecimento de proteção, soluções e assistência. Esse não é o caso em relação às áreas urbanas" (ibidem, p. 13). 
a ótica do deslocamento forçado e vice-versa. Ou seja, como fazer dialogar os debates críticos sobre a questão urbana com as temáticas recorrentes do campo de estudos sobre refúgio (refugee studies), notadamente atreladas às questões de proteção, às políticas de fronteirização e às práticas de resistência? Este artigo busca promover um movimento preliminar de mapeamento de duas leituras recorrentes da questão dos refugiados urbanos, ancoradas elas próprias em interpretações específicas sobre o papel social da cidade e sobre a natureza do fenômeno do refúgio. De um lado, discute-se a cidade (enquanto espaço de governança territorial e social) e o refúgio (enquanto instituto de reterritorialização e estabilização de corpos em movimento) como instâncias fortemente controladas e disciplinadas por aparatos institucionais, entendidas assim enquanto dinâmicas de 'policiamento' (Rancière, 1999). De outro, lê-se o urbano e a experiência do refúgio como espaços de transformação e expressão de resistência e de afirmação subjetiva da liberdade (Mezzadra, 2004), delimitadas aqui em uma interpretação do refúgio e do urbano como processos de politização e não como meros produtos da política governamental. Embora organizadas para fins heurísticos como dois polos do debate, entendemos que se trata de leituras sobrepostas e interrelacionadas na prática, articuladas na junção da cidade como espaço concebido - planejado, articulado e estrategicamente produzido - e espaço vivido - habitado, reconfigurado e ressignificado por práticas sociais (Zhang, 2006) - e da condição refugiada como categoria burocrático-jurídica e vida biográfica (Fassin, 2007).

Na primeira parte, revisitamos parte da literatura que pensa as cidades como espaços de (re)produção da autoridade soberana estatal, nos quais a população refugiada está submetida a diferentes estratégias de controle e regulação. Desse grupo, recuperaremos os trabalhos que refletem sobre a ressonância das políticas estatais de refúgio sobre a vida cotidiana desses indivíduos e, na sequência, aqueles que iluminam os processos de fronteirização que acontecem nas cidades. Na segunda parte, resgatamos autores que exemplificam mecanismos de ressignificação do urbano por populações refugiadas para refletir sobre o potencial de transformação e contestação contido nas cidades, realçando-se as práticas de apropriação e reconstituição simbólico-material em contextos urbanos. À guisa de conclusão, ponderamos sobre o potencial que a interlocução entre estudos urbanos e estudos de migração forçada podem trazer para a reflexão sobre a condição refugiada e as políticas de pertencimento contemporâneas.

\section{A cidade policial e o refugiado policiado}

Importante conclusão emanada dos debates sobre os limites das democracias contemporâneas encontra-se no reconhecimento do esgotamento das formas liberais de fazer política com a respectiva conversão dos espaços, 
formas e procedimentos decisórios em mecanismos de reprodução de poder e domínio ${ }^{3}$. Rancière argumenta que a política foi hoje convertida em 'polícia', i.e., o gerenciamento e gestão de (dis)posições de poder que tomam como dada uma certa repartição do sensível (Rancière, 1999). Entende-se assim, por exemplo, que, na visão da política como polícia, a distinção entre cidadãos e estrangeiros, entre aqueles que podem participar da comunidade e aqueles que dela são excluídos, é tomada como natural e consensual, e cumpre ao poder soberano garantir que essa repartição de direitos e atribuições seja mantida e ordenada. A democracia existe assim como mecanismo de produção de um consenso mínimo sobre as fronteiras que separam aqueles que fazem parte e que 'contam' em relação aos demais.

A política propriamente dita, para Rancière, refere-se ao rompimento radical dessa 'ordem natural' das coisas por meio, sobretudo, do dissenso. A política é definida pela dinâmica de contestação dos processos que constituem as partes do jogo político e pelas disputas que seus significados engendram. É justamente essa irredutibilidade da disputa a uma lógica unívoca, singular e universal que constitui a essência do político. Não se trata apenas de uma reação dos sujeitos (subordinados) aos seus soberanos, mas da própria noção de que essas categorias são dotadas de sentido e de que a elas se atribuem determinadas posições no jogo social. Refere-se assim ao político como a dinâmica produzida por aqueles que não têm (fazem) parte. O político, no limite, trata da própria reinvenção da política, dos seus limites espaciais, temporais e subjetivos.

Essa distinção nos parece particularmente importante para situar a discussão sobre a relação entre a cidade e o refúgio, como categorias analíticas e sociais. Conforme esclarece Darling (2016), a subsunção da cidade e do refúgio e, por conseguinte, da questão dos refugiados urbanos sob a ótica da polícia tem prevalecido em grande parte da literatura. A leitura policial remete às práticas e políticas - tecnológicas e organizacionais - voltadas para monitorar e controlar a população: para tornar os não-contáveis (uncountable) em contáveis (countable) e, assim, dar forma ao que surge como ininteligível (e ameaçador) à ordem concebida (Rancière, 1999). Os trabalhos nesta linha iluminam as práticas de governança e disciplinarização que atravessam o processo de inserção dos refugiados na cidade (El-Kayed, Hamann, 2018; Grabska, 2006; Lebuhn, 2013). Revelam, assim, as diferentes formas pelas

\footnotetext{
3 Essa conclusão parece comum tanto aos críticos que procuram resgatar o liberalismo político e/ou a democracia representativa a partir de sua transformação e/ou radicalização (Benhabib, 2001; Habermas, 1997; Rawls, 1999) quanto àqueles que denunciam a sua imbricação com formas contemporâneas de exclusão e produção de injustiça sistêmica (Agamben, 2000; Wacquant, 2008).
} 
quais o Estado e seu aparato administrativo se materializam na vida cotidiana desses indivíduos.

As cidades surgem como ponto de apoio fundamental às preocupações estatais com a preservação da ordem nacional das coisas (Malkki, 1995). Seus espaços são geridos pela compreensão convencional do direito a habitar e pertencer, atrelado ao reconhecimento formal, expresso, em última instância, pela posse da cidadania. Como consequência, a presença de refugiados e solicitantes consolida-se como um problema ou um excedente, nos termos de Rancière. Em resposta, desenvolve-se um aparato governamental disposto a organizar e conformar esse excedente à ordem vigente. É nessas estratégias e tecnologias pensadas para controlar, conter ou expulsar os sujeitos que se expressa a dimensão policial das cidades (Darling, 2016).

De particular interesse são os estudos dedicados a refletir sobre o impacto do aparato burocrático-administrativo atrelado ao refúgio sobre a vivência de solicitantes e refugiados no meio urbano, nos quais a construção da política urbana aparece sob a esteira de uma cidade policial que está articulada à conversão e reprodução da condição e do corpo refugiado como lócus de seu controle ${ }^{4}$. Nesse sentido, a condição urbana se acopla à condição refugiada para a produção e reprodução de fronteiras territoriais (por exemplo, na contenção espacial de refugiados em guetos e áreas designadas) e simbólicas (de preconceitos raciais, étnicos, nacionais, de gênero que se materializam na interação com esses grupos).

Assim, para além das práticas de controle comuns a todos os habitantes das cidades, refugiados e solicitantes estão submetidos a uma série de procedimentos burocrático-administrativos que moldam suas experiências cotidianas. A exigência de ter de esclarecer a todo momento sua condição; de comprovar seu estatuto migratório para atos cotidianos, como reportar um crime à autoridade policial ou receber atendimento médico, além da existência de normas específicas a regular sua permanência e circulação ${ }^{5}$ são só algumas das instâncias que revelam a penetração estatal na esfera do vivido. Embora as

\footnotetext{
4 Interessante notar que, historicamente, a figura do estrangeiro mobilizou tanto a xenofobia, quanto a xenofilia. Se em determinados momentos, prevaleceu a percepção do estrangeiro como estranho e ameaçador à sociedade de acolhida; em outros, foram convidados a adentrar a nação e para ela contribuir. Esse foi o caso, por exemplo, de refugiados do Leste para países ocidentais durante a primeira fase da Guerra Fria, interpretados e mobilizados como defensores dos direitos civis, da liberdade política e dos valores liberais. O que não significa que seu processo de integração e sua presença tenham sido geridos e recebidos univocamente de forma pacífica e desejada. Essa ambivalência é explorada em diversos estudos históricos como: Marrus, 1985; Honig, 2002; Sassen, 1999.

5 Por exemplo, em alguns países, solicitantes são proibidos de residir em determinadas zonas urbanas e/ou de circular fora de determinados territórios. No Brasil, refugiados devem solicitar autorização ao governo para saída do país e devem comunicar à Polícia Federal qualquer mudança de endereço, sob as penas da lei, inclusive sob pena de perder o estatuto.
} 
normas do refúgio não determinem univocamente os fatos sociais atrelados à vida biográfica de refugiados, criam um espaço epistêmico de interação social que influencia e condiciona as possibilidades de apropriação e participação desses indivíduos no espaço urbano. A vida burocrática do refúgio, como define Young, pode limitar o acesso a serviços e espaços da cidade (Young, 2011).

Entre os elementos que apontam para as práticas de controle específicas sobre refugiados, Young destaca o caso de jovens solicitantes de refúgio em uma escola pública canadense. Apesar de ocultarem seu estatuto migratório com o intuito de não serem vistos como diferentes, atividades escolares cotidianas expunham sua condição migratória recorrentemente e evidenciavam as barreiras invisíveis a separar esses jovens dos demais alunos (ibidem). A participação em atividades externas, por exemplo, era condicionada à apresentação de um cartão que comprovasse a cobertura por um seguro de saúde, do qual, como solicitantes de refúgio, não dispunham. A ausência do documento tornava a negociação para viabilizar sua participação mais burocratizada e a subordinava à apresentação de um ofício nos quais os pais assumiam integralmente a responsabilidade por qualquer dano que pudesse acontecer a seus filhos. A demanda documental, atrelada a uma política de suposta inclusão universal ao sistema de ensino, criava barreiras 'informais' ao acesso ao direito, gerava atritos na relação entre pais, alunos solicitantes e a escola e dificultava o processo de integração.

No caso em questão, a ausência do documento estava diretamente atrelada à demora na resposta estatal aos pedidos de reconhecimento do estatuto. Além de marcar diferenças no acesso à participação das atividades escolares, a indefinição sobre a solicitação de refúgio dificultava a construção de um sentimento de pertencimento por parte desses jovens ao ambiente escolar, ao passo em que a iminência de ter que deixar tudo para trás caso tivessem seu pedido indeferido os assombrava e reforçava seu sentimento de exclusão.

No Brasil, o longo tempo para se julgar os pedidos de refúgio geram problemas semelhantes ${ }^{6}$. O protocolo provisório, que funciona como documento de identificação enquanto o pedido aguarda julgamento, é comumente rejeitado por órgãos públicos e privados por não ser reconhecido como um documento de identificação convencional’ . Além disso, a incerteza

\footnotetext{
6 Segundo dados do Comitê Nacional para os Refugiados (CONARE), existem hoje mais de 85 mil solicitações de refúgio aguardando resposta - o que torna o Brasil o $6^{0}$ país em número de solicitações acumuladas. Para saber mais: Mello, 2018.

7 Como nos aponta Facundo (2017, p. 113), "Às pessoas que consigam ativar a solicitação de refúgio lhes é entregue um 'protocolo' que funciona como documento de identidade e que dá acesso ao SUS, à rede de ensino público e permite tramitar outros documentos importantes para a vida empregatícia e civil brasileira como o CPF e a carteira de trabalho".
} 
sobre o futuro mantém a vida desses solicitantes de refúgio em permanente estado de suspensão (e suspeição), gerando dificuldades práticas para sua inserção à sociedade brasileira. Como relatam Lacerda e Gama (2016) uma solicitante teve sua possibilidade de emprego negada sob a justificativa de seu empregador de que "não contrataria alguém que poderia ser obrigada a ir embora no dia seguinte do país" (ibidem, p. 72). A história da solicitante anônima ilustra como as barreiras burocráticas atreladas aos processos de elegibilidade se materializam na vida cotidiana dessas pessoas, assim como o enorme desconhecimento por parte da sociedade de acolhida de suas especificidades.

A proliferação dessas barreiras remonta ao aumento dos deslocamentos de países do Sul em direção ao Norte, especialmente na década de 90. Para frear esses fluxos e impedir seu acesso ao refúgio, os processos de elegibilidade se transformaram em verdadeiros labirintos burocráticos. A proteção da pessoa cedeu lugar à regulação estrita do instituto jurídico e à concomitante criminalização dos solicitantes (Scheel, Squire, 2014). De um lado, a categoria de refugiados foi fracionada em múltiplas categorias de quase-refugiados, que oferecem formas de proteção paliativas em detrimento da proteção internacional e dos direitos previstos pela Convenção de 1951 (Zetter, 2007). De outro, foram estabelecidos critérios formais e processuais restritivos que tornaram o reconhecimento legal uma possibilidade cada vez mais remota e inacessível. Foi nesse contexto que ganharam força expressões de cunho pejorativo como refugiados econômicos, refugiados ilegais e bogus asylum seeker - todas reforçando a ideia de mobilização indevida do sistema de refúgio por migrantes econômicos que alegariam razões de perseguição como meio de conseguir proteção.

Em resposta, a mobilidade passou a ser regida por um complexo aparato governamental. Externamente, mais recursos e financiamento foram direcionados para agentes e atividades de fiscalização, para a construção de infraestruturas avançadas de regulação e vigilância, assim como para implementação de tecnologias biométricas na gestão das fronteiras e dos corpos em movimento. Na esteira do crescente policiamento sobre as fronteiras externas, as cidades passaram a desenvolver e praticar seus próprios modos de vigilância e regulação que traduzem e, por vezes, ressignificam as políticas nacionais para os contextos urbanos específicos.

As cidades garantem a capilarização das estratégias de policiamento por uma rede ampliada de atores, serviços e espaços. Como frisa Walsh (2014), não se trata do deslocamento do poder estatal, mas de sua difusão. As agências governamentais ainda detêm a prerrogativa do controle migratório. Este, no entanto, tem sido cada vez mais compartilhado, formal e informalmente, entre outros agentes - o que indica que essa difusão é menos um indício de retrocesso 
do Estado e mais um sinal do reforço desse aparato. Como consequência, o controle excede o aparato formal estatal e se espalha por práticas, relações e interações cotidianas.

Assim, "espaços públicos, serviços urbanos, locais de trabalho se tornam locais nos quais o alcance punitivo do policiamento fronteiriço pode se materializar a qualquer momento, muitas vezes pelas mãos daqueles intitulados cidadãos responsáveis" (Darling, 2016, p. 184). Suas ações buscam recuperar os sistemas tradicionais de pertencimento e identidade frente a um Estado que enxergam como incapaz de performar com eficácia suas funções (Walsh, 2014). Fazem-no regulando a presença do "outro", percebido como ameaçador e menos merecedor - o que tem consequências perniciosas para as vidas diárias de refugiados e solicitantes.

A ressonância dos regimes estatais de policiamento das fronteiras no espaço urbano permite atentar para a indissociabilidade do (inter)nacional e do local. As cidades revelam-se, assim, um enclave fundamental para transmissão e também intensificação dos discursos e práticas estatais. No entanto, o olhar sobre sua dimensão policial ainda fornece um quadro incompleto. Como nos lembra Lefebvre, as cidades também trazem consigo o potencial para transformação e emancipação. É sobre este potencial que trataremos a seguir.

\section{O político urbano e o direito ao refúgio na cidade}

Se o urbano é o espaço das coações, Lefebvre nos lembra que repousa nele igualmente as sementes da revolução (1999). Das ações cotidianas e espaços de sociabilidade espontâneas, argumenta, surgem novas práticas e possibilidades de apropriação e transformação da cidade em completo desacordo e desafio à ordem hegemônica. Para enxergá-las, porém, é necessário superar os campos cegos, despojando-se de velhos conceitos e percebendo as sementes das mudanças plantadas por novos atores, práticas e lugares (Lefebvre, 2001).

Parte desse campo cego se constitui pela questão dos refugiados urbanos. Se as estratégias de policiamento são uma dimensão essencial das vivências de solicitantes de refúgio e refugiados no meio urbano, resumi-las a essa dimensão é fornecer um quadro incompleto. Não se trata de relativizar os efeitos do aparato estatal na vida desses indivíduos - reais e concretos, como evidenciamos na seção anterior. Mas iluminar como os espaços da cidade têm funcionado como plataforma para processos que não apenas os de regulação, administração e controle. Como sugerem Uitermark e Nicholls (2014), o urbano é constituído pela tensão inexorável entre o papel de policiamento das cidades e seu potencial para politização - entendido como a possibilidade de subversão e transformação da ordem hegemônica. A compreensão dessa 
ambivalência permite avançar uma leitura mais nuançada do processo de inserção de refugiados e solicitantes no meio urbano: leitura que reconhece que as cidades ao mesmo tempo em que ressoam e aprofundam compreensões estadocêntricas sobre direitos e pertencimento, também abrigam processos que as desafiam.

Sob essa perspectiva, destacamos os trabalhos que ilustram como a apropriação de diferentes espaços das cidades em manifestações e protestos de solicitantes de refúgio e refugiados foi fundamental para redefinir os limites do espaço político. Analisando os movimentos de solicitantes argelinos contra o governo canadense, em 2002, que tomaram os espaços públicos de Montreal ${ }^{8}$, Nyers (2011) mostra como ao transformar espaços públicos em locais de ocupação e deliberação para suas plataformas reivindicatórias, o grupo de solicitantes argelinos subverteu o papel tradicional dos solicitantes urbanos como objetos passivos de assistência - definidos por uma política de ausência e falta - em prol de sua afirmação como sujeitos de direitos. Retomaram, assim, por uma política de presença, a centralidade do contexto urbano para a produção do político como dissenso e da cidade como território de experimentação democrática.

No caso brasileiro, foi emblemático o protesto de solicitantes de refúgio palestinos por meio da ocupação das calçadas em frente ao ACNUR e, posteriormente, dos gramados frontais do Palácio Itamaraty, sede da diplomacia brasileira, em 2007. Reassentados no país após o fechamento do campo de refugiados em que moravam, na fronteira com a Jordânia, foram incluídos em um programa de assistência desenhado por organizações da sociedade civil, ACNUR e governos. O programa tinha como objetivo prover os meios necessários para sua plena integração à sociedade brasileira. Meses após a chegada, insatisfeitos com uma série de deficiências do programa, os solicitantes de refúgio rumaram à Brasília onde acamparam em frente à sede do ACNUR para protestar. Em um dos bairros mais nobres da capital, ocuparam as calçadas com seus pertences pessoais e lá ficaram por mais de um ano (Moulin, 2011).

A esses protestos se somaram outros tantos ocorridos na primeira década do século XXI em cidades como Nova Déli, Nairóbi e Kampala (Marfleet, 2007). Constituíram uma reação ao endurecimento das políticas contra a presença de solicitantes de refúgio no meio urbano, traduzido em detenções

8 Em 2002, o Canadá suspendeu a moratória aprovada em 1997 que, reconhecendo a violência existente no país africano, proibira a deportação de argelinos que haviam solicitado refúgio no país ao longo da década de 90 e cujos pedidos haviam sido negados. A decisão expôs milhares de argelinos ao risco de deportação e resultou na eclosão de protestos levados a cabo pelos próprios solicitantes que visavam sensibilizar a opinião pública sobre sua situação e exigir uma resposta político-legal. As agências migratórias canadenses foram o alvo preferencial de seus protestos. 
arbitrárias, abusos por parte de autoridades locais e até mesmo deportação forçada. O contexto hostil obrigou uma maior articulação coletiva entre eles, que ocuparam os espaços públicos para protestar por melhores condições de vida.

Em 2002, centenas de solicitantes birmaneses cercaram o escritório do ACNUR em Nova Déli para exigir que suas solicitações fossem processadas mais rapidamente e que aquelas que haviam sido negadas fossem revistas. Seguravam cartazes com frases como "Vítimas do ACNUR - Assassino Silencioso" (ibidem, p. 42). Em setembro de 2005, um grupo de solicitantes e refugiados sudaneses deu início a um protesto na praça Mustapha Mahmoud, no Cairo, que se prolongou por três meses. Demandavam principalmente participação nas decisões sobre os termos de sua proteção e assistência. Foram duramente reprimidos por forças polícias egípcias com um grau de violência que chocou testemunhas e resultou em várias mortes - incluindo de crianças (Grabska, 2006).

Demandas específicas à parte, todas essas manifestações reiveindicavam o direito de ter voz sobre os rumos de seu processo de inserção nas sociedades de recepção. Como resume De Genova (2015, p. 48), tais rupturas críticas:

confrontam (e afrontam) regimes políticos baseados na suposta "impossibilidade" de que, oficialmente, os não-cidadãos, sem direitos, possam assumir a bandeira da quase-cidadania, outorgando-se a autorização de falar, reconfigurando o espaço do público e reivindicando direitos.

Em uma perspectiva lefebvriana, ao tomarem os espaços públicos - a rua é entendida aqui como marco de uma política ativa, de demanda dirigida, de protesto - e reafirmarem sua presença, refugiados e solicitantes reivindicam seu direito à cidade, ou seja, o direito de participar e transformar a vida urbana em função de suas necessidades e desejos e em detrimento dos constrangimentos legais existentes. Se a ordem administrativa nega aos não-cidadãos a agência política para avançarem suas demandas, ao reafirmarem sua presença coletivamente nos espaços da cidade avançam uma concepção pragmática de cidadania, onde o direito de usufruir plenamente da vida urbana deixa de ser delimitado pelo estatuto legal e passa a englobar todos que a habitam (citadins). Estar na cidade torna-se a condição para viver a cidade ${ }^{9}$.

A apropriação coletiva de símbolos e espaços por solicitantes de refúgio e refugiados encontra-se articulada na cidade ao que Darling chama de 'política de presença'. Trata-se de reconhecer que a permanência e ocupação dos espaços urbanos por essas pessoas constitui-se numa forma de afirmar e assegurar que fazem parte da comunidade, mesmo em contextos em que

9 Sobre a política de presença e ocupação de não-nacionais em movimentos urbanos no Brasil, ver: Thomaz, 2018. 
seu estatuto migratório permaneça indefinido (Ferris, 2011). Nesse sentido, o slogan: "Nós aqui estamos e não vamos sair" - entoado por imigrantes, solicitantes de refúgio e refugiados nas manifestações que tomaram as ruas de várias cidades norte-americanas em protesto à $\mathrm{HR} 4437^{10}$, nos fala muito sobre as políticas de presença (De Genova, 2015).

Obviamente as práticas reivindicatórias e afirmativas da presença não se resumem ao espaço urbano. Como nos lembra Young (2011, p. 238), habitantes de locais não urbanos, como campos de refugiados, podem avançar reivindicações sobre tais espaços e negociar seu pertencimento em bases diárias. No entanto, as cidades ocupam um lugar central na lógica de funcionamento estatal. Como vimos, nelas se encontra um conjunto de autoridades governamentais que operam as compreensões excludentes de pertencimento e de política. Além disso, segundo Mitchell (2003):

[...] o direito à cidade é um grito, uma demanda (...) que tem força apenas na medida em que existe um espaço a partir do qual e dentro do qual esse grito e essa demanda são visíveis. No espaço público (...) as organizações políticas podem representar a si mesmas para uma população maior e, através dessa representação, imprimir alguma força a seus gritos e demandas. Ao reclamar o espaço em público, ao criar espaços públicos, os próprios grupos sociais tornam-se públicos.

Sendo assim, as cidades apresentam potencial de ressonância das políticas de contestação e produção de solidariedades transversais. A apropriação de espaços simbólicos e/ou marcados por forte segregação potencializam seus efeitos disruptivos e conferem visibilidade para suas demandas. Charles Tilly fala da "geografia simbólica" da ocupação desses lugares representativos do poder. Segundo ele, a geográfica simbólica inclui o uso de "monumentos emblemáticos, locais ou edifícios em dramatização de demandas, e a luta pelo controle de espaços públicos cruciais na validação de reivindicações de poder político" (Tilly, 2000, p. 137, tradução dos autores). Nesse sentido, a presença de argelinos nos escritórios de imigração canadense ou dos palestinos ocupando o gramado frontal do Palácio Itamaraty em Brasília constituem uma presença abjeta, uma anomalia preocupante para a ordem soberana (De Genova, 2015, p. 48).

Para além da dimensão simbólica, a apropriação de locais estratégicos permite uma maior interação e troca com atores diversos, o que potencializa

\footnotetext{
${ }_{10}$ Aprovada pela Câmara dos Deputados em 16 de dezembro de 2005, a HR4437, conhecida como Lei de Proteção das Fronteiras, Antiterrorismo e Controle da Imigração Ilegal continha um conjunto de medidas que visava aprofundar o controle do Estado sobre a imigração denominada "ilegal", incluindo a criminalização de todos os imigrantes sem documentos e de qualquer indivíduo ou instituição que lhes fornecesse auxílio. Devido à grande resistência e críticas que sofreu, foi derrotada no Senado.
} 
a repercussão das demandas do grupo. O encontro das diferentes escalas nas cidades permite que o alcance dessas pautas extrapole as fronteiras nacionais e ganhe repercussão mundial. No caso dos palestinos, a solidariedade dos habitantes de Mogi das Cruzes, uma das cidades onde foram reassentados, à sua causa resultou na criação de um blog com o objetivo de ajudar os palestinos a conquistar os direitos que lhes foram prometidos e expor as dificuldades pelas quais passavam (Moulin, 2011). Além disso, a imprensa internacional passou a veicular notícias sobre o caso - o que elevou o alcance da manifestação a uma audiência global (ibidem). É neste sentido que Sassen (1998, p. 17) afirma que, a "cidade é um sítio estratégico para os atores em desvantagem porque lhes permite ganhar presença para poder emergir como sujeitos, ainda quando não ganhem poder de maneira direta".

A ocupação das ruas, praças e demais espaços da cidade por indivíduos em situação de refúgio e seus corpos a partir de manifestações e protestos trata-se, no limite, de um exercício de cidadania que se constitui não como discurso jurídico-político, mas, essencialmente, como prática - que aponta em direção a novas formas de inclusão e pertencimento. Ao viabilizar o encontro, a reunião, a convivência, o espaço público torna possível a ação em conjunto a partir da qual são avançadas práticas de resistência e/ou subversão à ordem hegemônica e às suas contradições que se materializam na vida cotidiana. O espaço público recupera, assim, sua essência democrática no que tange à possibilidade da participação e discussão coletiva sobre os rumos das decisões que afetam suas vidas.

Nessa perspectiva, as práticas reivindicatórias e contestatórias que se concretizam nos espaços das cidades podem ser lidas como meios capazes de afetar não apenas o imaginário urbano como também o imaginário (inter) nacional. Ao ser encarada como lócus de práticas que desafiam a lógica governamental a vincular o direito de pertencer e de gozar de direitos à posse da cidadania, as cidades assumem importância estratégica como plataforma de combate a regimes políticos que excluem e segregam aqueles que "não tem parte".

\section{Notas finais}

Neste artigo, buscou-se analisar os constrangimentos, assim como as potencialidades que o espaço urbano oferece a populações refugiadas. Dentro do debate crítico sobre a questão urbana, mobilizamos especialmente as reflexões avançadas por Lefebvre para pensar o refúgio urbano. Das muitas vias que se abrem a partir desse diálogo, priorizamos a que nos permite pensar o urbano a partir da dialética entre o controle e a resistência ou, como definimos, entre o policiamento e a politização. A vivência do refúgio na cidade surge assim atravessada, por um lado, pelas regulamentações e práticas 
estatais de controle de fronteira e, por outro, por estratégias de contestação e subversão à ordem 'nacional' das coisas.

Nos espaços da cidade, as ideias prevalentes sobre pertencimento, refúgio e soberania implícitas nas políticas e práticas estatais se materializam e permeiam a vida cotidiana de solicitantes de refúgio e refugiados. O (crescente) controle sobre as fronteiras externas se traduz, em nível local, na multiplicação de fronteiras sociais que delimitam os termos e as possibilidades do refúgio. Neste sentido, enfocamos especialmente as exigências colocadas aos solicitantes pelo complexo aparato burocrático estatal. Como Young (2011, p. 555) coloca, "o poder do Estado não é ilimitado mas é particularmente insistente nas situações de refugiados aguardando uma decisão sobre seu caso". A indefinição acerca de seu pedido os coloca em uma posição de permanente transitoriedade na qual sua integração é prejudicada tanto pelas exigências documentais que não atendem como solicitantes, quanto pelo risco iminente de deportação no caso de serem recusados. O espraiamento dos aparatos de controle por diferentes espaços, atores e instituições aprofunda ainda mais as experiências de marginalização e exclusão, e revela que, mais do que espaços de ressonância, as cidades podem criar suas próprias barreiras ao refúgio.

Como nos lembra Harvey (2014, p. 12), porém, "há no urbano uma multiplicidade de práticas prestes a transbordar de possibilidades alternativas". A teoria urbana crítica, ao iluminar a vida cotidiana como lugar de resistência e da elaboração de estratégias de luta, permite pensar o refúgio urbano a partir de outra chave: a da politização. Buscamos evidenciar como, a despeito dos constrangimentos impostos por regulamentações e políticas de controle, solicitantes de refúgio e refugiados se apropriam coletivamente do espaço público como meio para avançar suas reivindicações. Ao se fazerem visíveis, fazem-se ouvidos. Redefinem, assim, os limites do político, moldado por concepções estadocêntricas de pertencimento que negam aos não-cidadãos o direito de participação e decisão. Ao usarem as ruas como plataformas para suas lutas e demandas, recuperam e atualizam a experiência da democracia direta, reivindicando o direito de definir os termos e conteúdo do refúgio. Se tais iniciativas não são capazes de transformar a ordem hegemônica, podem ao menos tensioná-la, trazendo à tona aberturas para construção de outros modos de solidariedade e articulação comunitária.

\section{Referências bibliográficas}

ACNUR (Alto Comissariado das Nações Unidas para Refugiados). Global trends forced displacement in 2016. 2017. Disponível em: <http://www.unhcr.org/ statistics/unhcrstats/576408cd7/unhcr-global-trends-2016.html>. Acesso em: 15.06.2018. 
ACNUR (Alto Comissariado das Nações Unidas para Refugiados). Global trends: forced displacement in 2017. 2018. Disponível em: <http://www.unhcr.org/ statistics/unhcrstats/5b27be547/unhcr-global-trends-2017.html>. Acesso em: 15.06.2018.

ACNUR (Alto Comissariado das Nações Unidas para Refugiados). UNHCR policy on refugee protection and solutions in urban areas. 2009. Disponível em: < http:// www.refworld.org/docid/4ab8e7f72.html>. Acesso em: 15.06.2018.

AGAMBEN, Giorgio. Means Without End: Notes on Politics. Minneapolis: Univ. of Minnesota Press, 2000.

BENHABIB, Seyla. Transformations of Citizenship: Dilemmas of the Nation State in the Era of Globalization. Amsterdã: Koninklijke Van Gorcum, 2001.

DARLING, Jonathan. Forced migration and the city: Irregularity, informality, and the politics of presence. Progress in Human Geography, v. 41, n. 2, p. 1-21, 2016.

DE GENOVA, Nicholas. As políticas queer de migração: reflexões sobre "ilegalidade" e incorrigibilidade. REMHU, Revista Interdisciplinar da Mobilidade Humana, v. 23, n. 45, p. 43-75, 2015.

EL-KAYED, Nihad; HAMANN, Ulrike. Refugees' Access to Housing and Residency in German Cities: Internal Border Regimes and Their Local Variations. Social Inclusion, v. 6, n. 1, p. 135-146, 2018.

FACUNDO, Ângela. Êxodos, Refúgios, Exílios: refugiados colombianos no Sudeste do Brasil. Rio de Janeiro: Papéis Selvagens, 2017.

FASSIN, Didier. Humanitarianism as a Politics of Life. Public Culture, v. 19, n. 3, p. 499-520, 2007.

FERRIS, Elizabeth. The Politics of Protection: the limits of humanitarian action. Nova lorque: Brookings Institution Press, 2011.

GRABSKA, Katarzyna. Marginalization in urban spaces of the Global South: Urban refugees in Cairo. Journal of Refugee Studies, v. 19, p. 287-307, 2006.

HABERMAS, Jügen. Direito e democracia: entre facticidade e norma. Rio de Janeiro: Tempo Brasileiro, 1997.

HARVEY, David. Cidades rebeldes: do direito à cidade à revolução urbana. São Paulo: Martins Fontes, 2014.

HONIG, Bonnie. Democracy and the Foreigner. Princeton: Princeton University Press, 2002.

LACERDA, Ana Luiza; GAMA, Carlos Frederico. O Solicitante de refúgio e a soberania moderna: a identidade na diferença. Lua Nova, São Paulo, n. 97, p. 53-80, 2016.

LEBUHN, Henrik. Local border practices and urban citizenship in Europe: Exploring urban borderlands. City, v. 17, p. 37-51, 2013.

LEFEBVRE, Henri. A revolução urbana. Belo Horizonte: Editora UFMG, 1999.

LEFEBVRE, Henri. O direito à cidade. São Paulo: Centauro, 2001. 
MALKKI, Liisa. Purity and Exile: Violence, Memory, and National Cosmology among Hutu Refugees in Tanzania. Chicago: University of Chicago Press, 1995.

MARFLEET, Philip. 'Forgotten', 'hidden': Predicaments of the Urban Refugee. Refuge, v. 24, n. 1, p. 36-45, 2007.

MARRUS, Michael. The Unwanted: European Refugees in the Twentieh Century. Oxford: Oxford University Press, 1985.

MELLO, Patrícia. Brasil é o sexto país com maior número de pedidos de refúgio acumulados. Folha de São Paulo, 2018. Disponível em: < https://www1.folha. uol.com.br/mundo/2018/06/brasil-e-o-sexto-pais-com-maior-numero-depedidos-de-refugio-acumulados.shtml>. Acesso em: 15.06.2018.

MEZZADRA, Sandro. The right to escape. Ephemera: theory \& politics in organization, v. 4, n. 3, p. 267-275, 2004.

MITCHELL, Don. The Right to the City. Minneapolis: University Press, 2003.

MOULIN, Carolina. Os direitos humanos dos humanos sem direitos: refugiados e a política do protesto. Revista Brasileira de Ciências Sociais, v. 26, n. 76, p. 145155, 2011.

NYERS, Peter. No one is illegal between city and nation. Studies in Social Justice, v. 4, n. 2, p. 127-143, 2011.

RANCIÈRE, Jacques. Dis-agreement: Politics and Philosophy. Minneapolis: University of Minnesota Press, 1999.

RAWLS, John. Collected papers. Ed. Samuel Freeman. Cambridge, Mass.; London, UK: Harvard University Press, 1999.

SASSEN, Saskia. Guests and Aliens. Nova lorque: New Press, 1999.

SASSEN, Saskia. Los espectros de la globalización. Buenos Aires: Fondo de Cultura Econômica, 1998.

SCHEEL, Stephen; SQUIRE, Vicki. Forced Migrant as "Illegal" Migrants. In: FIDDIAN-QASMIYEH, Elena; LOESCHER, Gil; LONG, Katy; SIGONA, Nando (eds.). The Oxford Handbook of Refugee \& Forced Migration Studies. Oxford: Oxford University Press, 2014.

TILLY, Charles. Spaces of Contention. Mobilization: An International Journal, v. 5, n. 2, p. 135-159, 2000.

THOMAZ, Diana. Uma cidade que transforma migrantes em sem-teto. Le Monde Diplomatique, 2018. Disponível em: < https://diplomatique.org.br/uma-cidadeque-transforma-migrantes-em-sem-teto/>. Acesso em: 15.06.2018.

UITERMARK, Justus; NICHOLLS, Walter. From politicization to policing: The rise and decline of new social movements in Amsterdam and Paris. Antipode, v. 46, n. 3, p. 970-991, 2014.

WACQUANT, Loïc. The Militarization of Urban Marginality: Lessons from the Brazilian Metropolis. International Political Sociology, v. 2, n. 1, p. 56-74, 2008.

WALSH, James. Watchful citizens: Immigration control, surveillance and societal participation. Social and Legal Studies, v. 23, n. 2, p. 237-259, 2014. 
YOUNG, Julie. 'A new politics of the city': Locating the limit of hospitality and practicing the city-as refuge. Acme, v. 10, n. 3, p. 534-563, 2011.

ZETTER, Roger. More Labels, Fewer Refugees: Remaking the Refugee Label in an Era of Globalization. Journal of Refugee Studies, v. 20, n. 2, p. 172-192, 2007.

ZHANG, Zhongyuan. What is lived space? Ephemera: theory \& politics in organization, v. 6, n. 2, p. 219-223, 2006.

Recebido para publicação em 31.01.2018

Aceito para publicação em 26.06.2018 Received for publication in in January 315t, 2018

Accepted for publication in June $26^{\text {th }}, 2018$

ISSN impresso 1980-8585

ISSN eletrônico 2237-9843

http://dx.doi.org/10.1590/1980-85852503880005314 